\title{
The Institute of Physics and The Physical Society
}

\author{
L. Cohen \\ Secretary, IPPS
}

Quantum Electronics Division, K.P. Meyer, Berne, forty one applications for Individual Ordinary Membership were collected at the recent Europhysics Conference on "Coherent Tunable Light Sources", held on 22 - 24 July in Munich.

\section{Grants from governments}

1) It has been announced by Professor S.F. Edwards that the United Kingdom government, through the intermediary of the Royal Society, has agreed to give $£ 4500$ to the European Physical Society provided a reasonable number of other governments give similar support.

2) Professor Ben-David expects to secure financial support from a public body in Israel, in the near future.

3) In a similar way the Royal Academy of Sciences, Sweden, will contribute an annual fee of $\$ 1000$.

At a UNESCO meeting in Paris on 25 June, attended by Ministers of Scientific Research, Professor Bernardini was invited to speak on "The European Physical Society as an example of effective scientific cooperation". It is hoped that this talk will encourage more European governments to help the EPS.

\section{How do I join?}

In accordance with Article 4 of the Constitution, membership of the EPS is in three categories:

a) Individuals (membership being open to all physicists irrespective of nationality or place of residence);

b) Societies, Groups or Laboratories;

c) Individuals, as under a), affiliated to a Society which itself has joined the European Physical Society as Member category $4 \mathrm{~b}$.

If a physicist IS an Individual Ordinary Member of the EPS, then:

1) he votes directly in the General Assembly;

2) he is eligible for office in the EPS;

3) he is eligible for membership of Council on behalf of the Individual Ordinary Members;

4) he may choose to become member of one or more Divisions of EPS:

5) he receives Europhysics News and the special Meetings Issue directly, without charge;

6) he receives all other publications by the Society Information Booklets, Summerschool Compendia, etc.) without charge (some of these upon request).

The membership fees for Individual Ordinary Members in 1970 are:

for category (a) above - 72 Swiss francs

for category (c) above - 18 Swiss francs

All applications for individual membership should be addressed to:

Main Secretariat

European Physical Society

P.O. Box 309

CH - 1227 Carouge-Geneva, Switzerland

An application form is included in this issue of Europhysics News.
The Physical Society was founded, in London, in 1874 as a learned Society for the dissemination of new knowledge in physics. Its membership was quite small but included both academic and non-academic physicists. During the 1914-18 war physics began to be recognized in Britain as a separate profession and the need for a professional body was acknowledged by many of the leading physicists, including Rutherford and the Braggs, and in 1918 The Institute of Physics was founded. The activities of the two organizations were largely complementary. There was considerable cooperation and collaboration and, of course, a considerable degree of overlap of membership.

The second world war gave another big boost to physics which led to a large increase in activity of both the Institute and the Society when the war was over. However, it was during the war that serious consideration was first given to the possibility of merging the two bodies and the amalgamation finally came about in 1960 with the creation of the present organization. Since the amalgamation, development has been particularly rapid - the membership for example has almost doubled and now stands at over 15000 .

\section{Membership}

The membership structure of the Institute and Society is complex because of its "qualifying" function. The function of the professional grades Fellow of the Institute, Associate of the Institute, Graduate of the Institute and Licentiate of the Institute - is to give recognition to the standing of the member, i.e. a combination of education, experience and attainment in physics. The other non-professional grades - Fellows of The Physical Society, Subscribers and Group Subscribers, participate only in learned Society activities and entry to these grades is relatively open. There is also a grade of Student membership.

The main "career" grade is that of Associate of the Institute which has about one third of the total member- ship, although at the moment the Graduate members are also about one third of the total. Well over 1000 members live outside the United Kingdom, distributed over most parts of the world.

\section{Publications}

The largest single activity is that of scientific publications which has been greatly expanded since 1960 in both the number of journals and in total bulk. The primary research journals known as the Journal of Physics series are published in five parts (shortly to be increased to six): A - General Physics, B - Atomic and Molecular Physics, C - Solid State Physics, D - Applied Physics and E - Scientific Instruments.

Two magazine type journals are also published, Physics Education (bimonthly), aimed at the level of senior classes in schools and the first year of university, and Physics Bulletin (monthly) which is the chief channel of communication between the central organization and the members but in addition has evolved into a topical magazine of interest to all physicists.

Review journals are receiving more prominence. "Reports on Progress in Physics" which was an annual publication is now a bi-monthly and publication of a new review journal in technological physics is about to start. Book publishing is largely confined to conference proceedings, of which two or three a year are issued.

\section{Meetings and conferences}

The Institute and Society is divided geographically into Branches, including one in New Zealand (the Australian Branch became the independent Australian Institute of Physics about six years ago). There is also a division into Subject Groups, currently numbering eighteen. The principal activity of the Branches is the holding of evening meetings but increasingly the range of activities is widening to include, for example, half-day and whole-day meetings on subjects of local interest.

The Groups are responsible for organizing most of the major confer- 
ences of which between twenty and twenty-five are held each year. In addition, the Groups hold evening, half-day and whole-day meetings as well as visits to laboratories and works. The conferences vary considerably in attendance (from 50 to 450 participants), the larger meetings tending to be those covering a broad field such as solid state physics, on which a conference has been held annually for the past seven years. An increasing number of conferences are being organized on an annual basis, in addition to solid state physics there is now an annual meeting on solid state devices, atomic and molecular physics, thin films and computational physics.

\section{Education}

The teaching of physics, at all levels, has been a matter of concern to the Institute and Society for many years. The most direct involvement is with the Higher National Certificates and Diplomas, and the Graduateship examination, but there is considerable involvement at school level, for example in new methods of teaching (Nuffield Project) and the "Physics at Work" exhibitions which are organized for the 13 to 15 year age group.

Physics Centres, which have developed within the last four years, give the opportunity for physics teachers in schools to meet each other and physics teachers in the universities, one aim being to emphasize that a physics teacher is a physicist as well as a teacher.

A new scheme, still in its pilot stage, is designed to help the school teacher in another way by linking him with a physicist in industry so that physics can be better set in its context of application. Yet another project is concerned with the relationship between university physics departments and industry, particularly concerning the nature of the first degree and of the $\mathrm{PhD}$ and their relevance to the needs of industry.

In addition to these special projects the Institute and Society collects and publishes information on courses in universities, polytechnics and technical colleges and on postgraduate work in these establishments.

\section{Exhibitions}

The annual Physics Exhibition has its origin in the exhibitions held by The Physical Society in the early years of the century. It has grown with the growth of the hardware of physics, particularly in the past twenty five years.

The special characteristic of the exhibition is that only new instru-

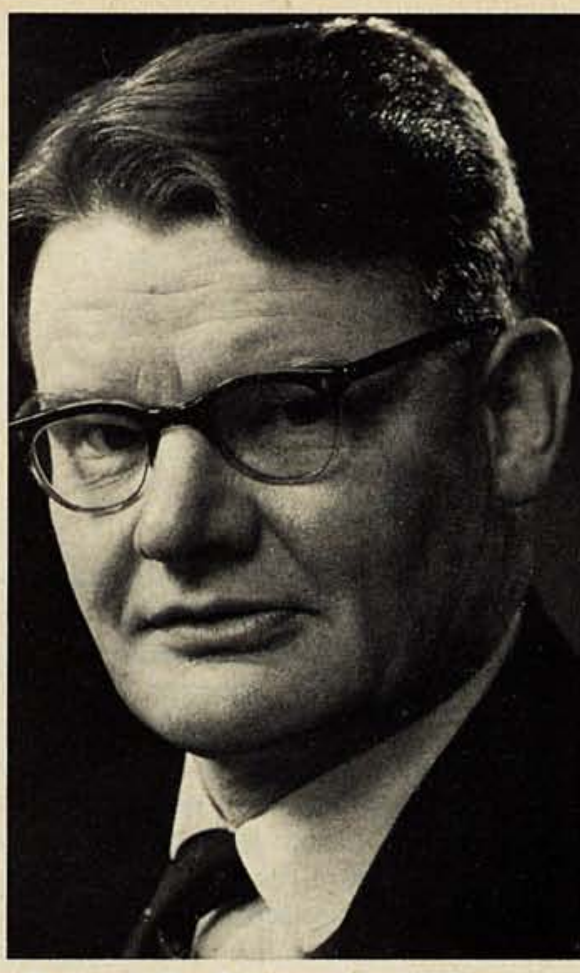

J.W. Menter, New President of the IPPS.

ments or devices may be shown and indeed many exhibits are in the prototype stage. Strict refereeing, similar to that employed for scientific journals, ensures that a high standard as a scientific event is maintained.

The regulations are modified from time to time to take into account changing circumstances. A recent change allows firms and universities from outside the UK to participate, in addition to the special national displays held by invitation.

\section{Awards}

The Institute and Society now awards twelve medals and prizes the oldest dates from 1907 and the newest was awarded for the first time in 1970. One, the Holweck Prize, is awarded jointly with the French Physical Society.

\section{Administration and Finance}

The overall control of the organization is in the hands of the elected Officers - President, four Vice-Presidents, Honorary Treasurer, Honorary Secretary and the Council of ten members. The Vice-Presidents are each responsible for a major sector of activity, namely: publications, membership and education, meetings and exhibitions. Their committees, along with finance and external and professional matters, form the framework within which the Institute and Society operates.

The day-to-day activities are carried out by a full-time staff numbering about ninety, under the general administration of the Secretary. With the exception of editorial work, all acti-

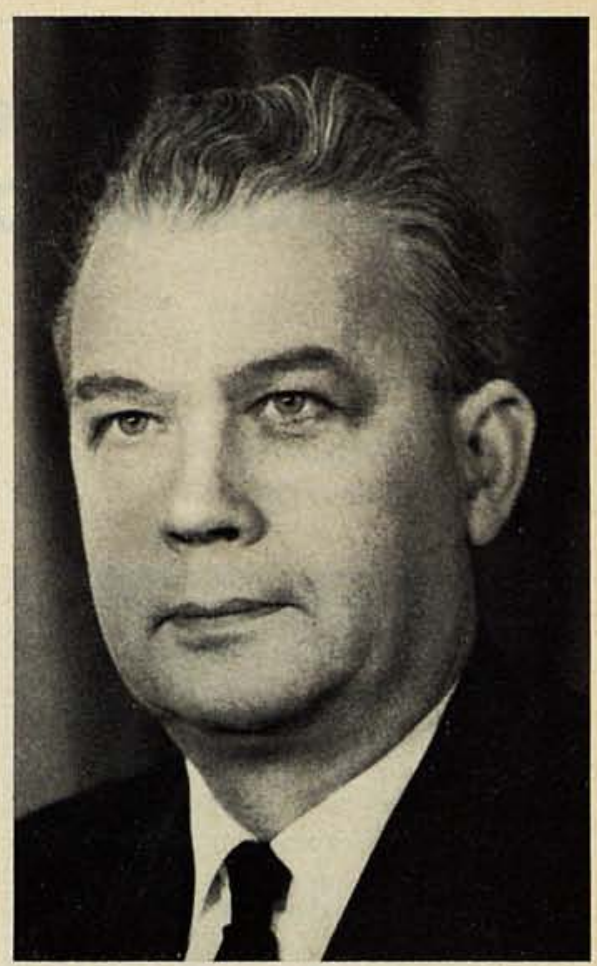

M.R. Gavin, Outgoing President of the IPPS.

vities are carried out from a house in Belgrave Square, London, which became the home of the Institute in 1946. The editorial office is at the old premises of The Physical Society in South Kensington, London, and to cope with the increasing activity in this field an additional editorial office has just been opened in Bristol.

The total financial turnover will exceed $£ 500000$ in 1970 and it is expected that a small surplus will be produced, due largely to the surplus made on publications since most other activities produce a deficit. With the exception of small sums for special projects, such as Physics Centres, no money is made available by the Government and all activities must therefore be made as nearly financially balancing as is possible.

\section{Future developments}

Pressure of space prevents more than a mention of several other aspects of the work of the Institute and Society, notably the ownership of the Fulmer Research Institute (a laboratory for sponsored research), the Benevolent Fund and the growing collaboration with other professional scientific societies (the Council of Science and Technology Institutes) and the engineering institutions.

The maintenance of growth of membership and activities is a major concern as is the means by which these activities can be financed. Last but not least is the expectation that the Institute and Society will play an increasing part in national and international affairs of concern to physics and physicists. 